\title{
Endovascular Treatment of Cerebral Arteriovenous Malformations
}

\author{
Caleb E Feliciano*, Erwin Rayo, Jorge Mendoza and Rafael Rodríguez-Mercado \\ Department of Surgery-Neurosurgery Section, University of Puerto Rico-Medical Sciences, San Juan, PR, USA
}

\begin{abstract}
Cerebral AVMs are still a matter of significant debate among neurological specialists. The role of intervention, medical therapy and observation is still being elucidated. Available management strategies seem to overlap, and establishing clear guidelines for individualized treatment plans depending on the available resources and expertise may contribute to management. The purpose of this report is to provide an update and recommendations from the endovascular standpoint regarding tools and techniques that we believe are key to improved outcomes. To this end, we review our cases, the current literature, and provide three illustrative cases. Improved understanding of the natural history of these complex lesions will help understand the effect that our interventions have upon them. In addition, careful evaluation of the characteristics and specific AVM risk factors, specifically pertaining to endovascular therapy, will be beneficial in establishing its role in any particular case.
\end{abstract}

Keywords: Cerebral arterio-venous malformation; Endovascular management; Tools and techniques

\section{Introduction}

A brain AVM is an abnormal connection between arteries and veins in the brain without an intervening network of capillaries [1]. Usually, there is no intervening neural tissue within the lesion, a congenital persistence of embryonic vessels [2-4]. As such, they are not fit to withstand normal blood pressures, with rupture and hemorrhage being a dreaded complication. The most common presentation is hemorrhage, followed by seizures, headaches and neurological deficits [2-4]. These may be explained as focal irritation with subsequent seizures, steal syndrome with symptoms of ischemia, and venous hypertension with headaches and/or focal neurological deficits. The natural history of these lesions is still being elucidated [3,5-8], as well as the role of intervention and medical therapy. Recently, the role of tetracyclines is being investigated as a vasculostatic agent in AVMs and aneurysms [9]. Aspirin also may have an anti-inflammatory role in aneurysm development [10]. These are examples of how understanding the interplay between the static and dynamic aspects of these vascular lesions and the possible role of inflammation and endothelial progenitor cells may contribute to their management in the future [1,11-13].

Classification of AVM has relied mainly on the Spetzler-Martin classification since 1986 [14]. Although the latter was developed for surgical purposes, it is customarily used for endovascular and radio surgical purposes due to ease and simplicity of use. Relationship to outcomes and prognosis is not entirely predicted whatsoever [15-17]. The endovascular approach success relates to the number of AVM feeders and embolization sessions [17], materials and devices employed and other angioarquitectural and hemodynamic characteristics of AVMs. The radio surgical approach and success of therapy relates more to the AVM volume [18]. Studies have not being able to completely validate the S\&M classification for endovascular therapy. There is a need for other prognostic tools and classification schemes [19], in order to have a sound estimation of risks and potential outcomes after endovascular therapy. The purpose of this report is to provide an update and some illustrative cases of the current status of endovascular AVM therapy.

\section{Indications and Contraindications}

The treatment of brain arteriovenous malformations has evolved significantly over the last decades. The introduction of endovascular and radio surgical techniques, as well as an improved understanding of the natural history of brain AVMs, has influenced decision-making.
Currently, combination of treatments, including open surgery, endovascular surgery, radio surgery and observation, is more common than in earlier days of treatment [20-23]. An individualized treatment agenda can go from just one modality to combination of all four (Figure 1). The ARUBA trial, $[5,24,25]$ at the least, has brought to attention that the behavior of unrupturedarteriovenous malformations may be more benign than priorly thought of. Endovascular management has reported cure rates ranging from 12 to $40 \%$ in some series [26-28]. In addition, there is a potential decrease in morbidity and mortality risks if adequate combination of treatments is undertaken, as opposed to exploiting only one modality [20]. We illustrate several cases (supplementary

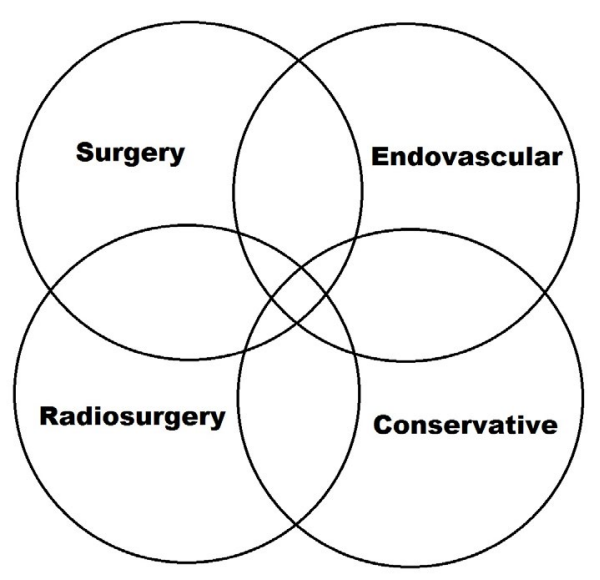

Figure 1: An individualized treatment plan can involve one modality or combination of all available four. These can be employed at different times and proportions.

*Corresponding author: Caleb E Feliciano, Department of Surgery-Neurosurgery Section, University of Puerto Rico-Medical Sciences, Campus, PO Box 365067, San Juan, PR 00936-5067, USA, Tel: 787-765-8276; Fax: 787-765-8276; E-mail: caleb.feliciano@upr.edu

Received September 01, 2013; Accepted December 17, 2013; Published January 02, 2014

Citation: Feliciano CE, Rayo E, Mendoza J, Rodríguez-Mercado R (2014) Endovascular Treatment of Cerebral Arteriovenous Malformations. Surgery Curr Res 4: 161. doi:10.4172/2161-1076.1000161

Copyright: (C) 2014 Feliciano CE, et al. This is an open-access article distributed under the terms of the Creative Commons Attribution License, which permits unrestricted use, distribution, and reproduction in any medium, provided the original author and source are credited. 

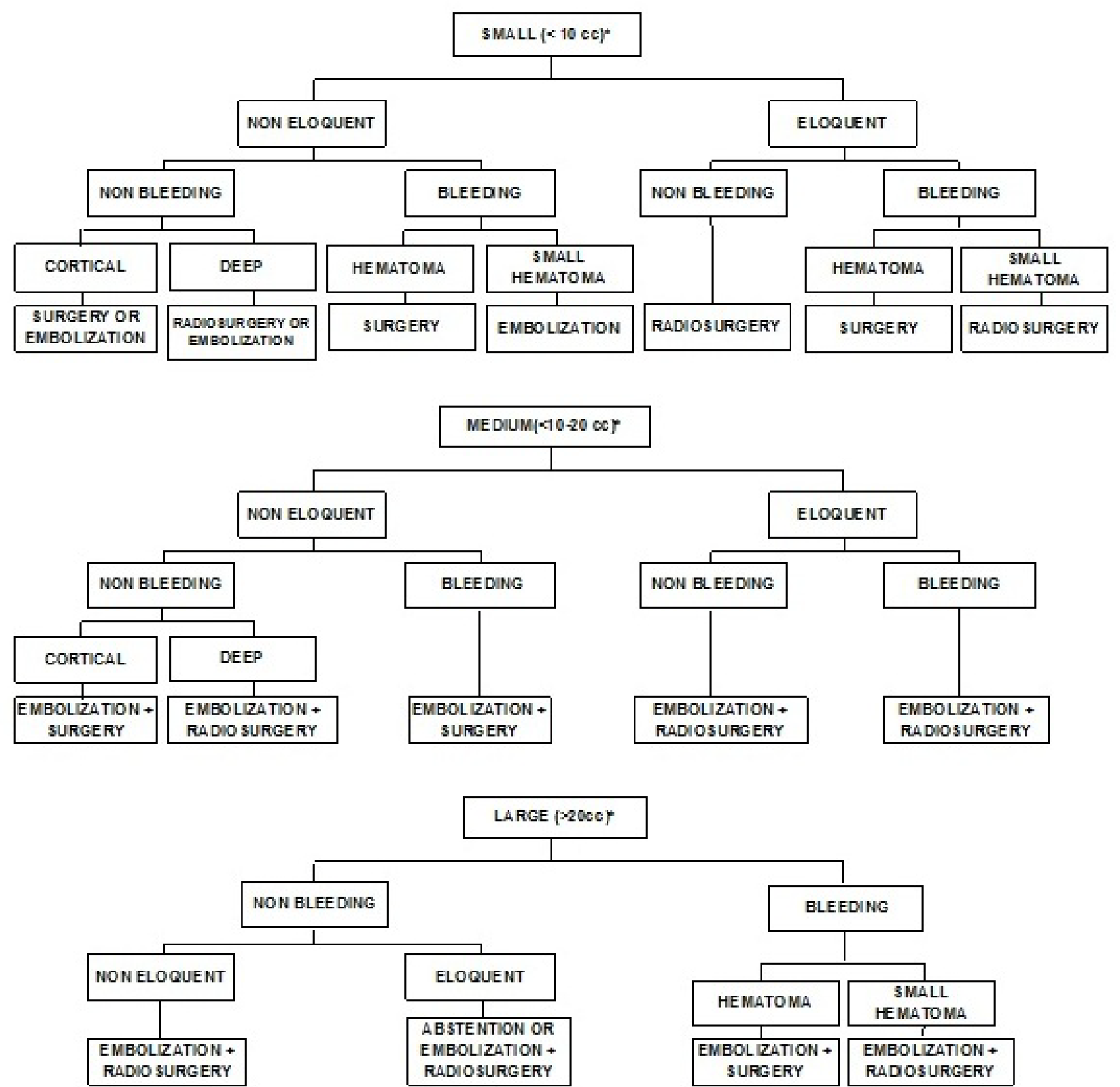

MANAGEMENT OF ARTERIOVENOUS MALFORMATIONS

\section{- The AVM volumen is calculated according a sphere area and calculated AxBxC/2 us ing MRI imsging}

Figure 2: Algorithm suggested by our group when management of an AVM favors intervention [29].

multimedia file) that point out the importance of adequate case and goal selection in order to attain successful results. The goal of endovascular therapy can go from cure, to either adjuvant treatment or palliation. Figure 2 shows an algorithm employed and suggested by our group when management of an AVM favors intervention [29]. These are guidelines based on the size and complexity of the lesion for a multimodal approach. An individualized treatment plan should also take into consideration the unique characteristics of the AVM, including risk factors for hemorrhage, neurological symptoms and signs, the resources available in a particular institution, operator experience, the patient's expectations and general medical condition.

\section{Approaches, Pitfalls and Complication Avoidance}

Between 1997 and 2004 a total of 648 patients were treated at our institution by the senior author, primarily by endovascular means [30]. There were 83 pediatric patients (13\%), 343 male (53\%) and 305 female (47\%) patients. $14.9 \%$ had Spetzler-Martin grade II arteriovenous 
malformations, $25.8 \%$ grade III, and $59.3 \%$ grade IV and V. The latter two grades underwent palliative treatment. Fifteen percent $(15.3 \%)$ of patients showed angiographic cure by endovascular therapy only. The rest continued to either surgical or radiosurgical therapy. There were a total of ten complications (1.5\%). Five patients $(0.7 \%)$ presented intracerebral hemorrhage without major long-term sequelae, of which three required surgical evacuation, and the rest were managed medically. There were four patients with transient ischemic deficits $(0.6 \%)$. In addition, one patient suffered a fatal intracerebral hemorrhage during embolization procedure (0.1\%).

The treatment of an AVM should start with a thorough understanding of the vascular pathoanatomy of the lesion. This entails knowledge of principal arterial feeders, including the presence of any important collaterals, flow-related or intranidal aneurysms, pattern of venous drainage, deep or superficial, fistulous, venous ectasias or stenoses, and proximity to eloquent areas. A complete description of the presenting symptoms is also paramount, whether hemorrhagic, seizures, chronic headaches, since the treatment may or may not actually be a good option for certain lesions or presentations [31]. The first decision is whether to treat or not to treat. After endovascular intervention is considered, the goal should be clarified, whether curative, adjuvant or palliative, to alleviate specific symptoms or to eliminate an identified risk factor for hemorrhage [22,32-34]. Delineating an adequate plan is the first defense against complications and poor outcomes.

Adequate selection of procedural tools and techniques is also of paramount importance. These include adequate selection of feeders, the use of provocative testing, [35] careful selection of embolization materials and concentrations, whether Onyx ${ }^{\oplus}$ or NBCA, and the sound use of coils and/or occlusion balloons in cases of fistulous component $[36,37]$. Regarding feeder selection, the usual way to go is with the highest flow feeder. Flow-guided microcatheters can assist with this selection. If aneurysm coils are anticipated a standard size microcatheter should be used. After reaching the target lesion, careful evaluation of images and superselective runs is important in order not to miss important collaterals that may become affected. The use of provocative testing can potentially improve sensitivity for small collaterals that are not easily visualized on angiographic images. At our institution we use a slow IA infusion of $7 \mathrm{mg}$ propofol $(20 \mathrm{secs})$ at the embolization pedicle [35], although other centers have reported using amobarbital [38], other medications like lidocaine [38] to evaluate central and peripheral white matter collaterals, or no provocative testing at all. The use of conscious sedation helps in the neurological exam. In patients where this is not an option, neurophysiological monitoring [39] may be an alternative. The use of either Onyx ${ }^{\bullet}$ or NBCA is primarily a preference of the operator. Nevertheless, the adequate concentration and knowledge of the chemical and biological behavior of the embolizant is very important to obtain the desired result. In the setting of an AVM with fistulous component, Onyx $x^{\oplus}$ may be an excellent alternative, but if preference or operator experience dictates otherwise, the use of NBCA at higher concentrations than 1:1, or with the assistance of aneurysm coils or flowarrest balloons may be adequate to get a more controlled embolization $[36,37]$. In adequate hands, both embolizants can potentially obtain the same efficacy and safety [40].

Finally, the volume of AVM embolized per procedure is important. The higher the volume, the more significant the hemodynamic changes will be. Consequently, postoperative blood pressure control should be more strict [41]. At our institution AVMs are embolized in stages, usually one feeder per session, lessening the risk for hemorrhage. The latter does not substitute for close neurological monitoring preferably in an ICU. This is more important with Onyx ${ }^{\oplus}$, where embolization volumes are usually higher, in average more than 50\% [40].
We illustrate several cases of AVMs treated at our institution. Selected films and angiographic views are shown in the supplementary video. The first patient is a 58-year-old male that harbored a symptomatic left frontal AVM that presented with intracerebral hemorrhage. The lesion was primarily fed by the left middle cerebral artery and was a Spetzler-Martin grade one. This patient was offered endovascular treatment after refusing surgery since it was believed to have a high probability for cure either way (one or two feeders, no noted important collaterals, prefrontal region, and no fistulous component). The result was excellent with NBCA embolization with no lesion noted on followup angiography. Another more recent case involved a 51-year-old female that had a history of chronic headaches and was found with a right parietal-occipital AVM fed primarily by the right middle cerebral artery. This case illustrates the use of coils when fistulous behavior is noted, a flow characteristic that likely increases the risk of endovascular treatment. The fistula was first addressed with aneurysm coils, and on sequential run-offs, thrombosis of the feeder was noted. There was no need for NBCA embolization afterwards. This patient is still pending follow-up angiography for possible staged embolization combined with radio surgery, but symptoms have significantly ameliorated. The last case is a 7-year-old girl that presented with cerebral hemorrhage requiring emergent craniotomy. Super selective angiography after recovery from initial surgery showed important collaterals to occipital cortex precluding safe embolization. The patient was subsequently taken for revision of craniotomy and AVM excision. She recovered to baseline after physical therapy and has remained in adequate neurological condition since then.

\section{Conclusion}

The success of AVM treatment rests on the continuous improvement in techniques and in the understanding of the natural history of these complex lesions. The latter will help understand the effect that our interventions will have upon them. In addition, careful evaluation of the characteristics and specific AVM risk factors, specifically pertaining to endovascular therapy, will be beneficial in establishing its role in any particular case.

\section{Surgical Pearls}

1. Small, low-flow, 1 to 2 feeder AVMs are amenable to cure. Careful angiographic evaluation for collaterals and super selective Wada when in doubt are of utmost importance.

2. High-flow AVMs may warrant the use of coils, balloons, high concentration NBCA or Onyx ${ }^{\oplus}$. Beware that fistulous behavior can increase false negative results of provocative testing.

3. Success of treatment depends on the goal of embolization, whether adjuvant, curative or symptomatic relieve.

4. Ruptured AVMs demand prompt attention and treatment due to increased risk for re-bleeding.

\section{References}

1. MoftakharP, Hauptman JS, MalkasianD, Martin NA(2009)Cerebralarteriovenous malformations. Part 2: physiology. Neurosurg Focus. 26:E11.

2. Tournade A, Riquelme C (2000) Advances in the endovascular treatment of intracranial arteriovenous malformations. Dialogues Clin Neurosci 2: 315-320.

3. Fleetwood IG, Steinberg GK (2002) Arteriovenous malformations. Lancet 359: 863-873.

4. Smith JL, Garg B (2002) Treatment of arteriovenous malformations of the brain Curr Neurol Neurosci Rep 2: 44-49.

5. Mohr JP, Moskowitz AJ, Stapf C, Hartmann A, Lord K, et al. (2010) The ARUBA trial: current status, future hopes. Stroke 41: e537-540. 
6. Stapf C, Mohr JP, Pile-Spellman J, Solomon RA, Sacco RL, et al. (2001) Epidemiology and natural history of arteriovenous malformations. Neurosurg Focus 11: e1.

7. Stapf C, Mohr JP, Choi JH, Hartmann A, Mast H (2006) Invasive treatment of unruptured brain arteriovenous malformations is experimental therapy. Curr Opin Neurol 19: 63-68.

8. Hartmann A, Mast H, Choi JH, Stapf C, Mohr JP (2007) Treatment of arteriovenous malformations of the brain. Curr Neurol Neurosci Rep 7: 28-34.

9. Frenzel T, Lee CZ, Kim H, Quinnine NJ, Hashimoto T, et al. (2008) Feasibility of minocycline and doxycycline use as potential vasculostatic therapy for brain vascular malformations: pilot study of adverse events and tolerance. Cerebrovasc Dis 25: 157-163.

10. Hasan DM, Mahaney KB, Brown RD Jr, Meissner I, Piepgras DG, et al. (2011) Aspirin as a promising agent for decreasing incidence of cerebral aneurysm rupture. Stroke 42: 3156-3162.

11. Moftakhar P, Hauptman JS, Malkasian D, Martin NA (2009) Cerebra arteriovenous malformations. Part 1: cellular and molecular biology. Neurosurg Focus 26: E10.

12. Gao P, Chen Y, Lawton MT, Barbaro NM, Yang GY, et al. (2010) Evidence of endothelial progenitor cells in the human brain and spinal cord arteriovenous malformations. Neurosurgery 67: 1029-1035.

13. ZhuGe Q, Zhong M, Zheng W, Yang GY, Mao X, et al. (2009) Notch-1 signalling is activated in brain arteriovenous malformations in humans. Brain 132: 3231 3241.

14. Spetzler RF, Martin NA (1986) A proposed grading system for arteriovenous malformations. J Neurosurg 65: 476-483.

15. Hartmann A, Pile-Spellman J, Stapf C, Sciacca RR, Faulstich A, et al. (2002) Risk of endovascular treatment of brain arteriovenous malformations. Stroke 33: $1816-1820$

16. Starke RM, Komotar RJ, Otten ML, Hahn DK, Fischer LE, et al. (2009) Adjuvant embolization with $\mathrm{N}$-butyl cyanoacrylate in the treatment of cerebral arteriovenous malformations: outcomes, complications, and predictors of neurologic deficits. Stroke 40: 2783-2790.

17. Kim LJ, Albuquerque FC, Spetzler RF, McDougall CG (2006) Postembolization neurological deficits in cerebral arteriovenous malformations: stratification by arteriovenous malformation grade. Neurosurgery 59: 53-59.

18. Milker-Zabel S, Kopp-Schneider A, Wiesbauer H, Schlegel W, Huber P, et al (2012) Proposal for a new prognostic score for linac-based radiosurgery in cerebral arteriovenous malformations. Int J Radiat Oncol Biol Phys 83: 525532.

19. Feliciano CE, de Leon-Berra R, Hernandez-Gaitan MS, Rodriguez-Mercado $R$ (2010) A proposal for a new arteriovenous malformation grading scale for neuroendovascular procedures and literature review. P R Health Sci J 29: 117-

20. de Oliveira E, Tedeschi H, Raso J (1998) Comprehensive management of arteriovenous malformations. Neurol Res 20: 673-683.

21. Thines L, Dehdashti AR, da Costa L, Tymianski M, ter Brugge KG, et al (2012) Challenges in the management of ruptured and unruptured brainstem arteriovenous malformations: outcome after conservative, single-modality, or multimodality treatments. Neurosurgery 70: 155-161.

22. Hurst RW, Berenstein A, Kupersmith MJ, Madrid M, Flamm ES (1995) Deep central arteriovenous malformations of the brain: the role of endovascular treatment. J Neurosurg 82: 190-195.

23. Fernández-Melo R, López-Flores G, Cruz-García O, Jordán-González J, FelipeMorán A, et al. (2003) [Modes of treatment for arteriovenous malformations of the brain]. Rev Neurol 37: 967-975.

24. Stapf C (2010) The rationale behind "A Randomized Trial of Unruptured Brain AVMs" (ARUBA). Acta Neurochir Suppl 107: 83-85.
25. Mohr JP (2008) A randomized trial of unruptured brain arteriovenous malformations (ARUBA). Acta Neurochir Suppl 103: 3-4.

26. Lasjaunias P, Manelfe C, Terbrugge K, Lopez Ibor L (1986) Endovascular treatment of cerebral arteriovenous malformations. Neurosurg Rev 9: 265-275.

27. Valavanis $A, Y a \AA ̋$ Yrgil MG (1998) The endovascular treatment of brain arteriovenous malformations. Adv Tech Stand Neurosurg 24: 131-214.

28. Yu SC, Chan MS, Lam JM, Tam PH, Poon WS (2004) Complete obliteration of intracranial arteriovenous malformation with endovascular cyanoacrylate embolization: initial success and rate of permanent cure. AJNR Am J Neuroradiol 25: 1139-1143.

29. Beltramello A, Zampieri P, Ricciardi GK, Piovan E, Pasqualin A, et al. (2005) Combined Treatment of Brain AVMs: Analysis of Five Years (2000-2004) in the Verona Experience. Interv Neuroradiol 11: 63-72.

30. Puentes J (2008) "Manejo Endovascular de Malformaciones Arteriovenosas Cerebrales Hemisfericas". In: Pedroza A, Quintana L, Perilla T (Eds.), "Tratado de Neurocirugia Vascular Latinoamericana" (pp. 451-59). Bogota, Colombia: Legis, SA.

31. Lv X, Li Y, Jiiang C, Yang X, Wu Z (2010) Brain arteriovenous malformations and endovascular treatment: effect on seizures. Interv Neuroradiol 16: 39-45.

32. Krings T, Hans FJ, Geibprasert S, Terbrugge K (2010) Partial "targeted" embolisation of brain arteriovenous malformations. Eur Radiol 20: 2723-2731.

33. Hartmann A, Mast H, Mohr JP, Pile-Spellman J, Connolly ES, et al. (2005) Determinants of staged endovascular and surgical treatment outcome of brain arteriovenous malformations. Stroke 36: 2431-2435.

34. Jafar JJ, Davis AJ, Berenstein A, Choi IS, Kupersmith MJ (1993) The effect of embolization with $\mathrm{N}$-butyl cyanoacrylate prior to surgical resection of cerebral arteriovenous malformations. J Neurosurg 78: 60-69.

35. Feliciano CE, de Leon-Berra R, Hernandez-Gaitan MS, Torres HM, Creagh O et al. (2013) Provocative test with propofol: experience in patients with cerebral arteriovenous malformations who underwent neuroendovascular procedures. AJNR Am J Neuroradiol 31:470-5.

36. Jan van Rooij W, Sluzewski M (2007) Endovascular occlusion of high-flow intracranial arteriovenous shunts: technical note. Neuroradiology 49: 1029 1031.

37. Newman CB, Hu YC, McDougall CG, Albuquerque FC (2011) Balloon-assisted Onyx embolization of cerebral single-channel pial arteriovenous fistulas. J Neurosurg Pediatr 7: 637-642.

38. Barr JD, Mathis JM, Horton JA (1994) Provocative pharmacologic testing during arterial embolization. Neurosurg Clin N Am 5: 403-411.

39. Niimi Y, Sala F, Deletis V, Berenstein A (2000) Provocative Testing for Embolization of Spinal Cord AVMs. Interv Neuroradiol 6: 191-194.

40. Loh Y, Duckwiler GR (2011) A prospective, multicenter, randomized trial of the Onyx liquid embolic system and N-butyl cyanoacrylate embolization of cerebral arteriovenous malformations. Clinical article. J Neurosurg 113: 733-41.

41. Spetzler RF, Wilson CB, Weinstein P, Mehdorn M, Townsend J, et al. (1978) Normal perfusion pressure breakthrough theory. Clin Neurosurg 25: 651-672. 